\title{
Compensatory Upregulation of Myelin Protein Zero-Like 2 Expression in Spermatogenic Cells in Cell Adhesion Molecule-1-Deficient Mice
}

\author{
Hiroki Nakata', Tomohiko Wakayama ${ }^{1}$, Kannika Adthapanyawanich ${ }^{1}$, \\ Takumi Nishiuchi $^{2}$, Yoshinori Murakami ${ }^{3}$, Yoshimi Takai ${ }^{4}$ and Shoichi Iseki ${ }^{1}$ \\ ${ }^{1}$ Department of Histology and Embryology, Graduate School of Medical Science, Kanazawa University, 13-1 Takara-machi, \\ Kanazawa, Ishikawa 920-8640, Japan, '2Division of Functional Genomics, Advanced Science Research Center, Kanazawa \\ University, 13-1 Takaramachi, Kanazawa, Ishikawa 920-8640, Japan, ${ }^{3}$ Division of Molecular Pathology, Department of \\ Cancer Biology, Institute of Medical Science, The University of Tokyo, 4-6-1, Shirokanedai, Minato-ku, Tokyo 108-8639, \\ Japan and ${ }^{4}$ The Division of Molecular and Cellular Biology, Department of Biochemistry and Molecular Biology, Kobe \\ University Graduate School of Medicine, Kobe, Hyogo 650-0017, Japan
}

Received November 14, 2011; accepted December 1, 2011; published online January 24, 2012

\begin{abstract}
The cell adhesion molecule-1 (Cadm1) is a member of the immunoglobulin superfamily. In the mouse testis, Cadm1 is expressed in the earlier spermatogenic cells up to early pachytene spermatocytes and also in elongated spermatids, but not in Sertoli cells. Cadm1-deficient mice have male infertility due to defective spermatogenesis, in which detachment of spermatids is prominent while spermatocytes appear intact. To elucidate the molecular mechanisms of the impaired spermatogenesis caused by Cadm1 deficiency, we performed DNA microarray analysis of global gene expression in the testis compared between Cadm1deficient and wild-type mice. Out of the 25 genes upregulated in Cadm1-deficient mice, we took a special interest in myelin protein zero-like 2 (Mpzl2), another cell adhesion molecule of the immunoglobulin superfamily. The levels of Mpzl2 mRNA increased by 20-fold and those of Mpzl2 protein increased by 2-fold in the testis of Cadm1-deficient mice, as analyzed with quantitative PCR and western blotting, respectively. In situ hybridization and immunohistochemistry demonstrated that Mpzl2 mRNA and protein are localized in the earlier spermatogenic cells but not in elongated spermatids or Sertoli cells, in both wild-type and Cadm1-deficient mice. These results suggested that Mpzl2 can compensate for the deficiency of Cadm1 in the earlier spermatogenic cells.
\end{abstract}

Key words: cell adhesion molecule, immunoglobulin superfamily, knockout mouse, spermatogenesis, testis

\section{Introduction}

Spermatogenesis is a complex process consisting of mitosis of spermatogonia, meiosis of spermatocytes, and transformation of spermatids (spermiogenesis) which occurs within the seminiferous tubule. It is well established that spermatogenesis is regulated by a variety of endocrine and

Correspondence to: Shoichi Iseki, Department of Histology and Embryology, Graduate School of Medical Science, 13-1 Takaramachi, Kanazawa 920-8640, Japan.

E-mail: siseki@med.kanazawa-u.ac.jp local secretory factors [13]. Another essential factor for the regulation of spermatogenesis is cell adhesion molecules responsible for the direct interaction between spermatogenic and Sertoli cells. Apical ectoplasmic specialization (ES) is a structure formed between elongated spermatids and Sertoli cells near the apical surface of seminiferous epithelium. Several cell adhesion molecules are known to be involved in the apical ES $[15,16,27]$. Most of these molecules belong to the immunoglobulin superfamily (IGSF), which is characterized by extracellular regions that contain immunoglobulin (Ig)-like domains [2]. Studies using knockout mice have indicated that deficiency of some of 
the IGSF molecules, such as junctional adhesion moleculeC (Jam-C), Nectin-2 and Nectin-3, leads to male infertility due to impaired spermatogenesis $[6,8,14]$.

Cell adhesion molecule-1 (Cadm 1$)$, originally reported as spermatogenic immunoglobulin superfamily (SgIGSF) [22], tumor suppressor in lung cancer 1 (Tslc1) [10] and nectin-like molecule-2 (Necl-2) [18], is a member of the IGSF and expressed in many mouse organs including the nervous system, testis, liver, and lung [24]. In the testis, Cadm1 is expressed exclusively in spermatogenic cells but not in Sertoli cells. In spermatogenic cells, Cadm1 is expressed in intermediate spermatogonia through to early pachytene spermatocytes as well as in step 7 and later spermatids, whereas it is not expressed in middle pachytene through to step 6 spermatids [23, 24, 26]. Cadm1 not only forms homophilic binding with the same molecule present on spermatogenic cells, but also heterophilic binding with another cell adhesion molecule poliovirus receptor (Pvr), that is present on Sertoli cells [23, 26]. Mice deficient for Cadm 1 are infertile due to impaired spermatogenesis with markedly reduced number of mature spermatozoa $[5,20$, $21,28]$, indicating that the cell-cell interaction involving Cadml plays an indispensable role in spermatogenesis. Histologically, the seminiferous epithelium of Cadm1deficient mice indicates prominent shedding of spermatids, particularly of step 7 to step 9 spermatids, into the lumen of seminiferous tubules [5, 21, 27, 28]. Also, the elongated spermatids remaining in the seminiferous tubules are irregular in shape and have incompletely condensed nuclei and poorly-developed flagella, indicating abnormal spermatid differentiation. In contrast, the earlier spermatogenic cells from intermediate spermatogonia through to early pachytene spermatocytes, despite the fact that these cells express Cadm 1 in wild-type mice, appear to be intact. Such a phenotype of Cadm1-deficient mice may not be explained simply by the loss of cell-cell contact due to Cadm 1 deficiency.

In the present study, we aimed to elucidate the molecular mechanisms underlying the impaired spermatogenesis in Cadm1-deficient mice. For this purpose, we investigated the global gene expression in the testis from Cadm1-deficient mice compared with that from wild-type mice, using the DNA microarray technique. We identified upregulation of the gene for myelin protein zero-like 2 (Mpzl2), another IGSF cell adhesion molecule, in the testis of Cadm1-deficient mice, and analyzed the expression and localization of Mpzl2 in the seminiferous tubules.

\section{Materials and Methods}

\section{Animals and tissue preparation}

All animal experiments were performed according to Guidelines for the Care and Use of Laboratory Animals in Kanazawa University. Cadm1-deficient 129Sv/C57BL6 strain mice (Cadm1-/-), which lack the entire exon 1 of the Cadm1 gene located on \#9 autonomic chromosome, were generated as described previously [26]. Male Cadm1- deficient mice were obtained by mating the female Cadm $1+/-$ with the male Cadm $1+/-$, and male wild-type mice $(\mathrm{Cadm} 1+/+)$ were also reared for use as control. Nectin3-deficient 129Sv/C57BL6 strain mice were generated as described previously [8]. In total, 22 Cadm1-deficient, 22 wild-type, and 3 Nectin-3-deficient male mice were used to obtain the present data. Unless otherwise indicated, the adult mice were used at the ages of 15 to $20 \mathrm{wk}$. Two female WKY/NCrj Wistar rats at 10 wk were purchased from Charles River Laboratories Japan, Inc. (Yokohama, Japan) for immunization. All animals were raised under standard laboratory conditions with a $12 \mathrm{hr}$-light/ $12 \mathrm{hr}$-dark cycle and free access to food and water. The mice were anesthetized with an intraperitoneal injection of sodium pentobarbital $(50 \mathrm{mg} / \mathrm{kg})$ and sacrificed by bleeding from the right atrium followed by transcardial perfusion with cold physiological saline. To isolate total RNA for microarray and reverse transcription-polymerase chain reaction (RTPCR) or to make cell lysates for Western blotting, the testes were dissected out, frozen immediately in liquid nitrogen, and stored at $-80^{\circ} \mathrm{C}$ until use. To make tissue sections, the animals were fixed by perfusion with cold 4\% paraformaldehyde in $0.1 \mathrm{M}$ phosphate buffer ( $\mathrm{pH} 7.2$ ), testes were dissected out and further fixed by immersion in the same fixative overnight at $4^{\circ} \mathrm{C}$. For in situ hybridization (ISH) and immunohistochemistry (IHC), the fixed specimens were rinsed overnight at $4{ }^{\circ} \mathrm{C}$ with $30 \%$ sucrose in $0.1 \mathrm{M}$ phosphate buffer and then frozen and cut into $8 \mu \mathrm{m}$ sections using a cryostat. Some fixed specimens were embedded in paraffin and cut into $4 \mu \mathrm{m}$ sections for PAS-hematoxylin staining. The sections were mounted on silanized glass slides (DAKO, Glostrup, Denmark).

\section{RNA preparation and microarray analysis}

Total RNA was isolated from the testis using an acid guanidinium-based solution (TRI reagent; Sigma-Aldrich, St. Louis, MO). For the microarray analysis, total RNA of testes from 3 animals in each experimental condition were mixed to represent each total RNA sample. Microarray experiment was performed using Whole Mouse Genome oligo DNA microarray kit (Agilent Technologies, Santa Clara, CA, USA) containing 44,000 probes for mouse genes according to the manufacturer's protocol. One $\mu \mathrm{g}$-aliquots of total RNA samples from the testes of wild-type and Cadm1-deficient mice were used to prepare Cy3- and Cy5labeled cRNAs, respectively, using a fluorescent labeling kit (Agilent Technologies). The two sets of fluorescent labeled cRNAs were combined and purified using an RNeasy RNA purification kit (Qiagen, Hilden, Germany). After hybridization with the cRNA solution and washing, the arrays were scanned under the maximum laser intensity for both the $\mathrm{Cy} 3$ and $\mathrm{Cy} 5$ channels using an Agilent microarray scanner (G2565BA). Images were analyzed using Feature Extraction software (version 7.0; Agilent Technologies).

\section{RT-PCR and quantitative RT-PCR}

First-strand cDNA was synthesized from a $1 \mu \mathrm{g}$-aliquot 
of the total RNA from each animal using the oligo-dT primer and reverse transcriptase (RT) (RevertraAce; Toyobo, Osaka, Japan). Using these cDNA samples, the conventional RT-PCR was performed for 28 cycles in a DNA thermal cycler (96-Well GeneAmp PCR System 9700; Applied Biosystems, Foster City, CA, USA), using Taq DNA polymerase (TaKaRa Ex Taq; Takara Bio Inc., Otsu, Shiga) and the following primer pairs: the Mpzl2 5'-primer (5'-CT ATGCAGTGTTGGCCTGAA-3'), the Mpzl2 3'-primer (5'TGTTGAGCTGGGGGTAAAAG-3'), the glyceraldehyde3-phosphate dehydrogenase (GAPDH) 5'-primer (5'-ACCA CAGTCCATGCCATCAC-3'), and the GAPDH 3'-primer (5'-TCCACCACCCTGTTGCTGTA-3'). The amplified products from 3 different animals were analyzed with agarosegel electrophoresis.

Quantitative RT-PCR was performed in a Stratagene Mx-3005P thermocycler (Stratagene, La Jolla, CA, USA) according to minimum information for publication of quantitative real-time PCR experiments (MIQE). SYBR green was used to detect the amplification of cDNA in a total volume of $20 \mu \mathrm{l}$ with the absolute quantitative, $\Delta \mathrm{Ct}$ method [17]. Each reaction consisted of $10 \mu \mathrm{l}$ of SYBR green, $1 \mu \mathrm{l}$ of cDNA sample, $0.5 \mu \mathrm{l}$ of each primer pair (10 $\mathrm{pmol} / \mu \mathrm{l})$, and $8 \mu \mathrm{l}$ of distilled water. Thermal cycling conditions were $10 \mathrm{~min}$ at $95^{\circ} \mathrm{C}$ followed by 45 cycles at $95^{\circ} \mathrm{C}$ for $40 \mathrm{sec}, 60^{\circ} \mathrm{C}$ for $30 \mathrm{sec}$, and $72^{\circ} \mathrm{C}$ for $30 \mathrm{sec}$. GAPDH was employed as an endogenous control to normalize the data. Each sample was analyzed in triplicates, and samples from 3 different animals were analyzed to determine each value.

\section{In situ hybridization (ISH)}

An oligonucleotide containing digoxigenin (DIG)labeled locked nucleic acid (LNA) (5'-AggGggggggaGg gagagaAataaA-3'; large capitals represent LNA) was purchased from Nippon EGT (Toyama) and used as the antisense probe for Mpzl2 mRNA. Melting temperature (Tm) of this LNA probe was predicted to be $75^{\circ} \mathrm{C}$ using the LNA Tm prediction tool which is accessible at http://natm.com. The antisense and sense LNA probes without DIG label were also used. ISH was performed as previously described [22]. Briefly, the 4\% paraformaldehyde-fixed cryostat sections of the mouse testis were treated successively at room temperature with proteinase $\mathrm{K}(10 \mu \mathrm{g} / \mathrm{ml})$ in Tris-EDTA buffer for $2 \mathrm{~min}$, and with $0.25 \%$ acetate anhydrate in $0.1 \mathrm{M}$ triethanolamine $(\mathrm{pH} 8.0)$ for $10 \mathrm{~min}$, washed in $4 \times$ sodium chloride/sodium citrate (SSC) and dehydrated in ethanol. The sections were then incubated with the DIG-labeled antisense probe $(10 \mathrm{pmol} / \mathrm{L})$ at $37^{\circ} \mathrm{C}$ for $15 \mathrm{hr}$ using a hybridization buffer containing 50\% deionized formamide, $2 \times \mathrm{SSC}, 10 \mathrm{mM}$ Tris- $\mathrm{HCl}(\mathrm{pH} 7.5)$, 1 mM EDTA (pH 8.0), $1 \times$ Denhardt's solution, $0.25 \%$ SDS, $250 \mu \mathrm{g} / \mathrm{ml}$ yeast tRNA and $10 \%$ dextran sulfate. As control, the excess of unlabelled antisense or sense probe $(1000$ $\mathrm{pmol} / \mathrm{L}$ ) were added to DIG-labeled antisense probe. After hybridization, the tissue sections were washed in $0.2 \times \mathrm{SSC}$ containing $2 \%$ bovine serum albumin at $37^{\circ} \mathrm{C}$ for $5 \mathrm{~min}$.
The hybridization signals were detected by incubating the sections successively with alkaline phosphatase-conjugated anti-DIG antibody (Roche Diagnostics, Basel, Switzerland) diluted at 1:600 in 0.1 M Tris- $\mathrm{HCl}, 150 \mathrm{mM} \mathrm{NaCl}, \mathrm{pH} 7.5$ and with the substrate Fast Red (DAKO, Glostrup, Denmark) in $50 \mathrm{mM}$ Tris- $\mathrm{HCl}$ (pH 9.5). The ISH results were confirmed in the testes from 3 different animals. To identify the stages of seminiferous tubules, some sections were stained in the acrosome with Alexa Fluor 488-conjugated lectin PNA (1:500; Molecular Probes, Eugene, OR, USA) and counterstained in the nucleus with bisbenzimide (Hoechst 33258; Sigma-Aldrich) at $100 \mathrm{ng} / \mathrm{ml}$.

\section{Preparation of primary antibodies}

Rabbit polyclonal anti-Cadm1 antibody was prepared as previously described [23]. Mouse monoclonal anti- $\alpha-$ tubulin (clone DM 1A) antibody was purchased from SigmaAldrich. Rat polyclonal antisera against mouse Mpzl2 was produced in our laboratory according to the method described previously, with modification [25]. Briefly, a cDNA fragment $96 \mathrm{bp}$ in length coding the carboxyl-termini of mouse Mpzl2 was cloned into the bacterial expression vector pGEX-6p-1 (Amersham Pharmacia Biotech, Uppsala, Sweden). By introducing this vector into the bacteria BL21 (Novagen, Madison, WI, USA), the recombinant oligopeptide for Mpzl2, which was 32-amino acids in length and fused with the carrier protein glutathione-S-transferase (GST), was produced. It was then emulsified with Freund's complete adjuvant and injected as antigen into the footpads of 2 female WKY/NCrj Wistar rats. A booster immunization was made two weeks later, and sera were collected one week after the booster.

\section{Western-blot analysis}

Western blotting was performed as previously described [27]. Twenty- $\mu \mathrm{g}$ aliquots of cell lysate from the mouse testis were subjected to SDS-PAGE and transferred to PVDF membranes (Bio-Rad Laboratories, Hercules, CA, USA). The blots were incubated with rat polyclonal antisera against mouse Mpzl2 (1:2000) or mouse monoclonal anti$\alpha$-tubulin antibody (1:2000). After being washed, the blots were further incubated with horseradish peroxidase-labeled secondary antibody against rat or mouse IgG (DAKO) at 1:5000 dilution. The immunoreaction was detected and its intensity was quantified in ImageQuant LAS-4000 mini (Fujifilm Medical, Tokyo) after treatment of the blots with the chemiluminescent reagent ECL-plus (Amersham Pharmacia Biotech). Samples from 3 different animals were analyzed to determine each value.

\section{Immunohistochemistry (IHC)}

IHC at the light microscopic level was performed as previously described [26]. Briefly, the 4\% paraformaldehyde-fixed cryostat sections of the mouse testis were first treated with $5 \%$ normal goat serum to prevent non-specific antibody binding and then incubated overnight at $4{ }^{\circ} \mathrm{C}$ with rat polyclonal antisera against mouse Mpzl2 (1:800) for 
single immunofluorescent microscopy, or with the mixture of the former antisera and rabbit polyclonal anti-Cadm 1 antibody $(10 \mu \mathrm{g} / \mathrm{ml})$ for double immunofluorescent microscopy. For negative control, normal rat sera (1:800) were used in place of the primary antibodies. After the sections were washed in PBS, the immunoreaction was visualized by incubating the sections with anti-rat IgG antibody conjugated with Alexa Fluor 594 (Molecular Probes) at 1:400 for single immunofluorescent microscopy, or with the mixture of the former antibody and anti-rabbit $\operatorname{IgG}$ antibody conjugated with Alexa Fluor 488 at 1:400 for double immunofluorescent microscopy, for $1 \mathrm{hr}$ at room temperature. The sections were then subjected to observation with an immunofluorescence microscope (BX50/BXFLA; Olympus, Tokyo). The IHC results were confirmed in the testes from 3 different animals. To reveal the histological features of seminiferous tubules, the paraffin sections were stained with PAS-hematoxylin and subjected to observation with a conventional microscope.

\section{Statistical analysis}

The statistical difference between two out of multiple mean values was examined by one-factor analysis of variance (ANOVA) followed by Bonferroni's post hoc test. Differences with a $\mathrm{P}$ value less than 0.05 were considered significant.

\section{Results}

\section{Increased expression of Mpzl2 $\mathrm{mRNA}$ in the testis of Cadm1-deficient mice}

To elucidate the molecular mechanisms underlying the impaired spermatogenesis caused by Cadm 1 deficiency, we performed DNA microarray analysis of the levels of global gene expression in the testes from Cadm1-deficient mice at 2, 5 and 20 wk postpartum compared with those from wildtype counterparts. The rationale for adopting these ages was that, during the normal testis development, pachytene spermatocytes with round shape and large nuclei first appear at 2 wk postpartum, and elongated spermatids (step 7 and later spermatids) at $5 \mathrm{wk}$ postpartum, in the luminal portions of seminiferous epithelia [1]. The expressions of 25 and 21 genes were found to be increased and decreased more than 1.5-fold, respectively, at all three ages of Cadm1-deficient mice (Fig. 1A, B; Table 1). As expected, Cadm1 itself was included in the 21 down-regulated genes.

Taking into account that the testis of Cadm1-deficient mice is lacking in normal later spermatids, we considered the upregulated genes to be more worthwhile to investigate than the downregulated ones. Therefore, quantitative RTPCR analysis was performed in the testes from adult wildtype and Cadm1-deficient mice on the mRNA for the 25 genes shown to be upregulated by DNA microarray analysis. The testis of Nectin-3-deficient mice, which are infertile due to impaired spermatogenesis, was also analyzed. We confirmed approximately 20 -fold increase of the mRNA for Mpzl2 in the testis from adult Cadm1-deficient mice compared with wild-type mice (Fig. 2A, B). No significant difference was noted in the levels of Mpzl 2 mRNA between wild-type and Nectin-3-deficient mice. The mRNA for $\mathrm{K}$ cnd2, a potassium channel gene, was also confirmed to be increased by RT-PCR, but the mRNA for all other genes were expressed at too small copy numbers in the testis (data not shown).

\section{Localization of Mpzl2 $\mathrm{mRNA}$ in the testes of wild-type and Cadm1-deficient mice}

We then examined the expression and cellular localization of Mpzl2 mRNA in the testes from wild-type and Cadm1-deficient adult mice with ISH analysis. We used a digoxigenin-labeled oligonucleotide probe containing LNA, a modified DNA nucleotide. LNA probes are known to increase the melting temperature and therefore the intensity and specificity of molecular hybridization. In the seminiferous tubules of wild-type mice, the signal for Mpzl2 mRNA was detected primarily in spermatocytes but not in sperma-
A

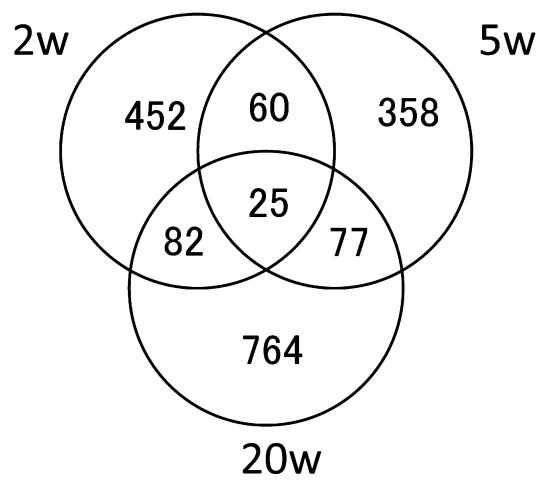

B

Down-regulated genes

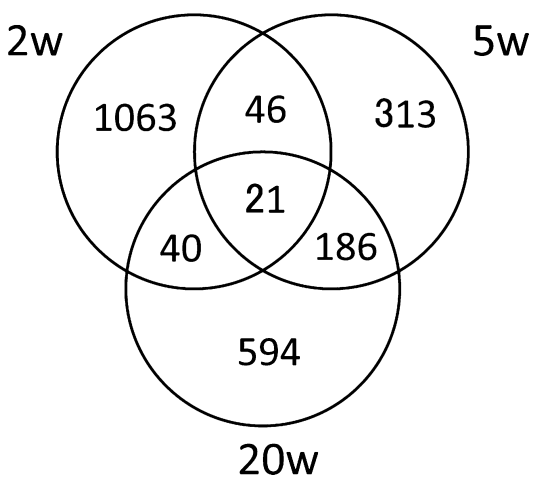

Fig. 1. Microarray analysis of the global gene expression in the testes of Cadm1-deficient mice at 2, 5 and 20 postnatal weeks (w) compared with those of wild-type mice. 
Table 1. List of up- and down-regulated genes in the testis common to all three ages of Cadm1-deficient mice compared with those of wildtype mice

\begin{tabular}{|c|c|c|}
\hline Gene & NCBI accession no. & fold change \\
\hline Kend 2 & NM_019697 & 4.59 \\
\hline \multirow[t]{2}{*}{ Mpzl2 } & NM_007962 & 4.55 \\
\hline & & 2.13 \\
\hline Gpr 182 & NM_007412 & 2.02 \\
\hline Blvrb & NM_144923 & 1.97 \\
\hline Tnfaip6 & NM_009398 & 1.88 \\
\hline Trim56 & NM_201373 & 1.85 \\
\hline Ei24 & NM_007915 & 1.84 \\
\hline Mdk & NM_010784 & 1.82 \\
\hline Hspa8 & NM_031165 & 1.76 \\
\hline Rnd2 & NM_009708 & 1.76 \\
\hline Col18al & NM_009929 & 1.75 \\
\hline Stt3a & NM_008408 & 1.63 \\
\hline $\operatorname{Trfr} 2$ & NM_015799 & 1.63 \\
\hline Atpla2 & NM_178405 & 1.62 \\
\hline Scrn2 & NM_146027 & 1.61 \\
\hline Smoc2 & NM_022315 & 1.60 \\
\hline Arhgef1 & NM_008488 & 1.57 \\
\hline Tnfrsf12a & NM_013749 & 1.56 \\
\hline \multirow[t]{2}{*}{ Pla2g15 } & NM_133792 & 1.56 \\
\hline & AK010169 & 1.55 \\
\hline Tuba3a & NM_009446 & 1.55 \\
\hline Myoz2 & NM_021503 & 1.52 \\
\hline \multirow[t]{2}{*}{ 5730437N04Rik } & NM_027457 & 1.51 \\
\hline & AK085343 & 1.50 \\
\hline \multirow[t]{4}{*}{ Prkar2a } & NM_008924 & 0.65 \\
\hline & AK087842 & 0.65 \\
\hline & AK006816 & 0.63 \\
\hline & AK077682 & 0.63 \\
\hline \multirow[t]{2}{*}{ Clec4g } & NM_029465 & 0.62 \\
\hline & AK045399 & 0.62 \\
\hline Odf2 & NM_013615 & 0.60 \\
\hline Rplp1 & NM_018853 & 0.57 \\
\hline \multirow[t]{2}{*}{ Ptgds } & NM_008963 & 0.56 \\
\hline & BE990773 & 0.50 \\
\hline Tctex2 & U21674 & 0.46 \\
\hline Fez1 & NM_183171 & 0.44 \\
\hline 9030425E11Rik & NM_133733 & 0.40 \\
\hline Myom2 & NM_008664 & 0.36 \\
\hline \multirow[t]{2}{*}{ Pcsk7 } & NM_008794 & 0.35 \\
\hline & AK007186 & 0.34 \\
\hline Hrasls5 & NM_025731 & 0.23 \\
\hline Hddc3 & NM_026812 & 0.16 \\
\hline Cadm 1 & NM_207675 & 0.06 \\
\hline Cadm1 & NM_207676 & 0.04 \\
\hline Nicn1 gene & AJ299741 & 0.03 \\
\hline
\end{tabular}

tids at all stages of the spermatogenesis defined by PNA lectin histochemistry (Fig. 3A, B). The signal intensity appeared to be increased in the seminiferous tubules of Cadm1-deficient mice compared with those of wild-type mice (Fig. 3C). No signal was detected in Sertoli cells, judging from the absence of signal in the basal- and apicalmost portions of seminiferous epithelium. The signal disappeared when excess unlabeled antisense or sense probe was added to the probe solution for negative control (Fig. 3D).

\section{Expression and localization of Mpzl2 protein in the testes of wild-type and Cadm1-deficient mice}

Using rat polyclonal antisera against mouse $\mathrm{Mpzl} 2$ polypeptide, we performed western-blot analysis of cell lysates obtained from the testes of adult wild-type and Cadm1-deficient mice (Fig. 4A, B). The immunoreactive band of $70 \mathrm{kDa}$ representing Mpzl2 protein was detected in the testes of both wild-type and Cadm1-deficient mice. The intensity of this signal was about 2-fold higher in Cadm1deficient mice than in wild-type mice.

The histological features of the seminiferous tubules of Cadm1-deficient mice were first compared with those of wild-type mice in PAS-hematoxylin stained paraffin sections (Fig. 5A, B). In Cadm1-deficient mice, shedding of spermatids, particularly those later than step 7, into the seminiferous tubular lumen was prominent. The number of elongated spermatids (step 10 and later) was reduced substantially, and the remaining elongated spermatids were irregular in shape. In contrast, the earlier spermatogenic cells up to pachytene spermatocytes appeared intact.

To examine the cellular localization of Mpzl2 protein, we performed IHC in cryostat sections of the adult Cadm1deficient and wild-type mouse testes (Fig. 6). In Cadm1deficient mice, immunostaining for Mpzl2 was found in both the seminiferous tubules and interstitial tissue (Fig. 6A). However, the immunoreactivity in the interstitial tissue, presumably in Leydig cells, was non-specific, because replacement of the primary antibody with normal rat serum resulted in the same immunostaining (Fig. 6B). In the seminiferous tubules of Cadm1-deficient mice, the signal for Mpzl2 protein was localized to leptotene/zygotene through to early pachytene spermatocytes but was not detected in late pachytene spermatocytes through to elongated spermatids (Fig. 6C). In wild-type mice, the immunoreactive cell populations were the same as in Cadm1deficient mice but the intensity of immunoreactivity was weaker (Fig. 6D). Double-immunofluorescence microscopy for Mpzl2 and Cadm1 in the seminiferous tubules of adult wild-type mice demonstrated that early spermatocytes express both Mpzl2 and Cadm1, whereas elongated spermatids express Cadm1 but not Mpzl2 (Fig. 7A, B, C).

\section{Discussion}

Mpzl2, originally identified in mouse thymus as epithelial V-like antigen1 (EVA1), is a membrane protein with 215 amino acid residues, consisting of a signal peptide, an extracellular domain with only one Ig-like loop, a transmembrane domain, and a short intracellular domain [7]. Mpzl2 belongs to the IGS and considered to perform homophilic interaction with the same molecule. In the adult 
A

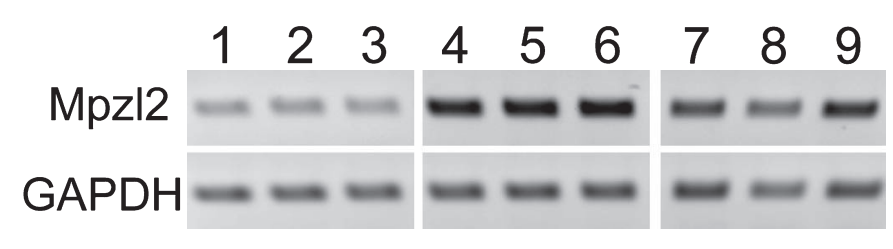

B

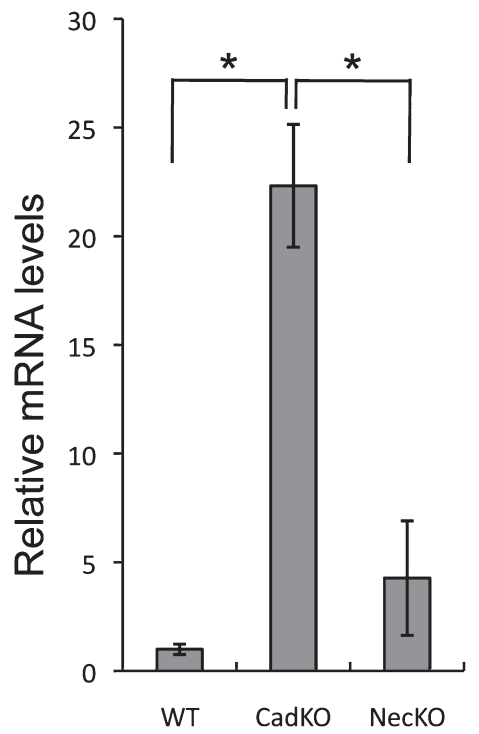

Fig. 2. (A) Conventional RT-PCR analysis showing the expression of Mpzl2 in the testes of wild-type (lanes1, 2, 3), Cadm1-deficient (4, 5, 6) and Nectin-3-deficient $(7,8,9)$ adult mice. Amplified products from the total RNA of the testis were electrophoresed and stained with ethidium bromide. Expression of GAPDH is shown as positive control. (B) Realtime quantitative RT-PCR analysis showing the expression of Mpzl2 in the testes of wild-type (WT), Cadm1-deficient (CadKO) and Nectin-3-deficient (NecKO) adult mice. The relative levels of Mpzl2 mRNA adjusted with the corresponding levels of GAPDH mRNA are indicated. Each value represents mean \pm SD of 3 samples. *Significantly different $(P<0.01)$
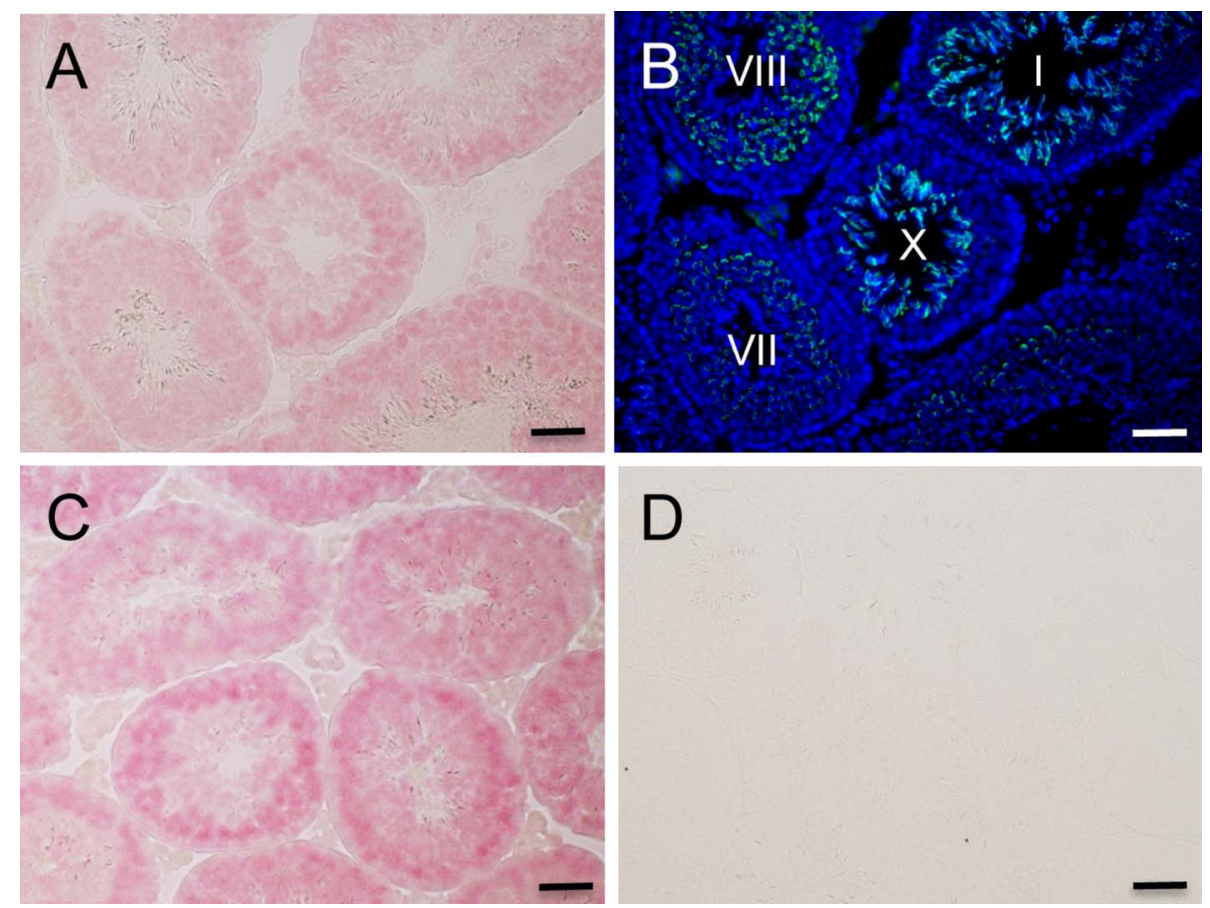

Fig. 3. (A, C, D) ISH analysis of the expression and localization of Mpzl2 mRNA in the testes of wild-type (A, D) and Cadm1-deficient (C) adult mice. Cryostat sections were hybridized with Dig-labeled antisense Mpzl2 probe in the absence (A, C) and presence (D) of excess unlabeled antisense probe, and the hybridization signal was visualized with alkaline-phosphatase histochemistry. (B) The same section as (A) was stained in the acrosomes with the PNA lectin histochemistry and in the nuclei with bisbenzimide. The spermatogenic stages of the seminiferous tubules are shown with roman numerals. Bar $=50 \mu \mathrm{m}$. 
A

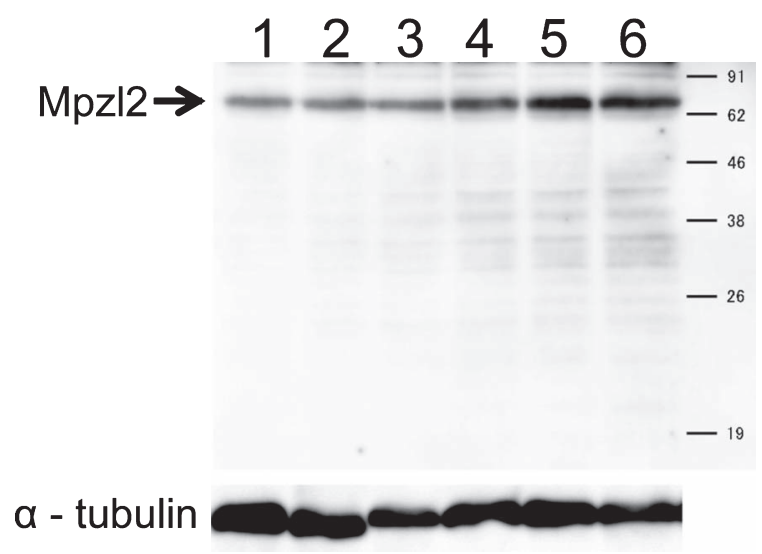

B

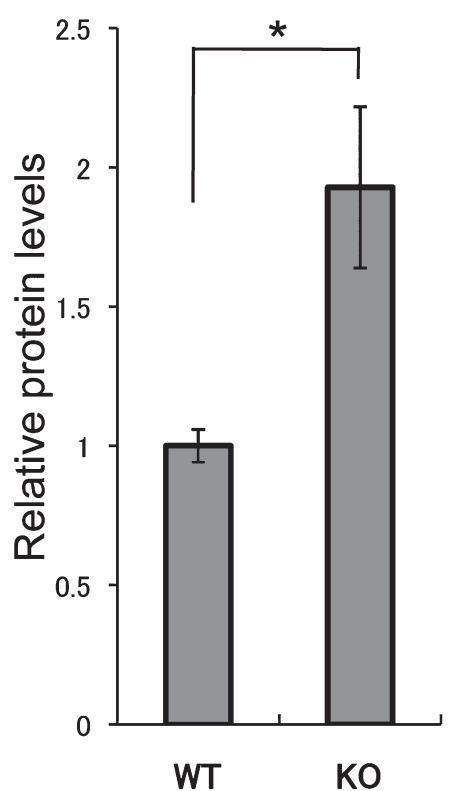

Fig. 4. Western blot analysis of the expression of Mpzl2 protein in the testes of wild-type (lanes 1, 2, 3) and Cadm1-deficient (4, 5, 6) adult mice. (A) The protein samples were electrophoresed, blotted and immunostained with rat anti-Mpzl2 antisera. For the control, staining with mouse anti- $\alpha$-tubulin antibody was also performed. The molecular weight scale is shown. (B) The relative levels of Mpzl2 in the wild-type (WT) and Cadml-deficient (KO) mice adjusted with the corresponding levels of $\alpha$-tubulin. Each value represents mean \pm SD of 3 samples. *Significantly different $(P<0.01)$.

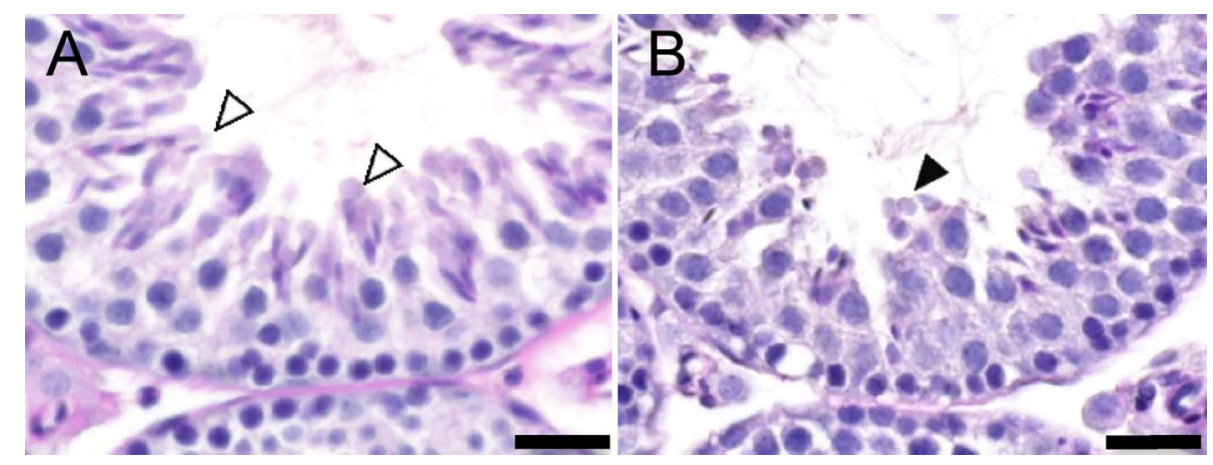

Fig. 5. Histological features of the seminiferous tubules of wild-type (A) and Cadm1-deficient (B) adult mice. Paraffin sections of the testes were stained with the PAS-hematoxylin method. Note that the elongated spermatids are lower in number and irregular in shape (black arrowhead) in Cadm1-deficient mouse, as compared with the normal step 12 elongated spermatids (white arrowheads) in wild-type mouse. $\mathrm{Bar}=50 \mu \mathrm{m}$.

mouse organs, Mpzl2 is expressed in the gut, kidney, liver, skin, testis, and thymus [7]. In the thymus, Mpzl2 is considered to be involved in the lymphocyte-stromal cell interaction, because it is expressed in thymocytes in the embryonic ages but in epithelial cells in the postnatal ages [4]. Transgenic mice overexpressing Mpzl2 in cortical epithelial cells of the thymus show increases in the size and absolute cell number of thymus, in spite of an increase of apoptosis in the thymus. Also, Mpzl2 is expressed in epithelial cells of the human choroid plexus and may play a role in the regulation of permeability in the choroid plexus barrier [3]. So far, no report is available on the generation of the knock-out mouse for Mpzl2, thus it is unknown if Mpzl2 is indispensable for spermatogenesis.

In the present results, the levels of Mpzl2 mRNA increased by 20 -fold and those of Mpzl 2 protein increased by 2 -fold in the testis from Cadm1-deficient mice compared with that from wild-type mice. Other cell adhesion molecules known to be expressed in spermatogenic cells, such as $\mathrm{N}$ cadherin (N-cad), Coxsackievirus and adenovirus receptor (CAR), Jam-C, and Nectin-3 [27], were not detected among the 25-up-regulated genes in microarray. We also confirmed 

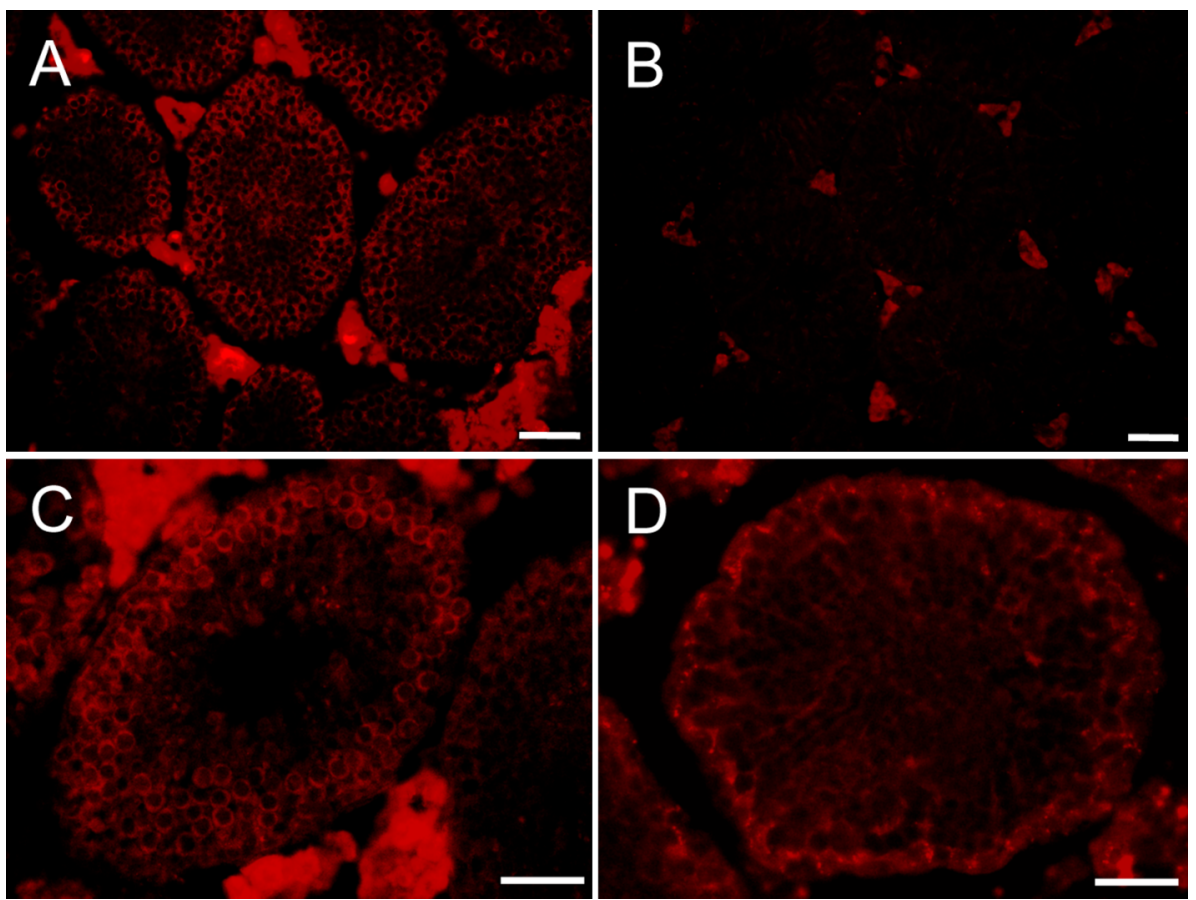

Fig. 6. Immunohistochemical localization of Mpzl2 in the testes of Cadm1-deficient (A, B, C) and wild-type (D) adult mice. Cryostat sections were immunostained with rat anti-Mpzl2 antisera $(\mathbf{A}, \mathbf{C}, \mathbf{D})$ or non-immune rat serum $(\mathbf{B})$. Note that the reactivity in the interstitial cells are detected without the primary antibody and thus is nonspecific. In both mice, Mpzl2-immunoreactivity is primarily localized in the earlier spermatogenic cells up to early pachytene spermatocytes. Bar $=50 \mu \mathrm{m}$.
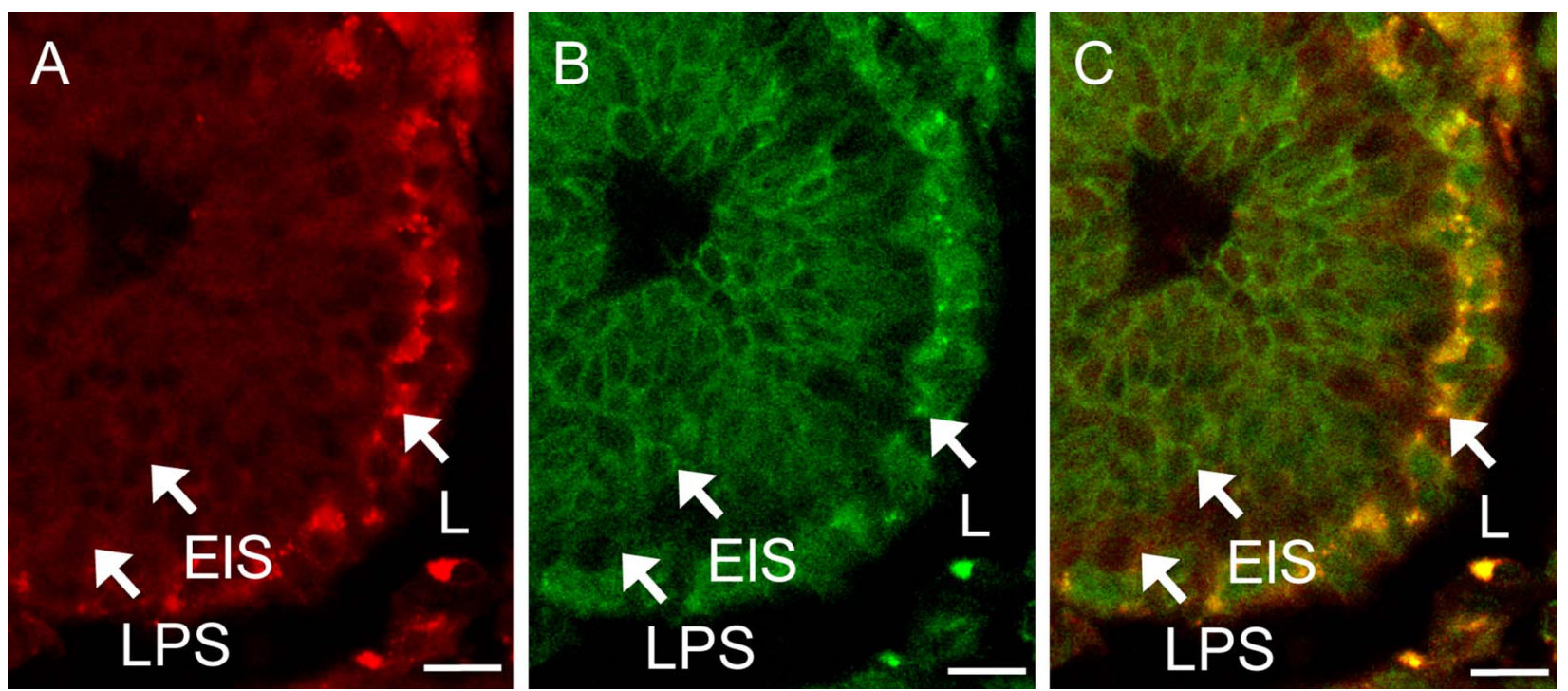

Fig. 7. Double immunostaining of the stage IX seminiferous tubule of a wild-type adult mouse with rat polyclonal anti-Mplz2 antisera and rabbit polyclonal anti-Cadm1 antibody. Note that in leptotene spermatocytes (L) the immunoreactivity for Mpzl2 (red, A) overlaps with that of Cadm1 antibody (green, B) when merged (yellow, C). In contrast, elongated spermatids (EIS) are immunopositive for Cadm1 but negative for Mpzl2, and late pachytene spermatocytes (LPS) are negative for both Mpzl2 and Cadm1. Bar=20 $\mu \mathrm{m}$.

with RT-PCR that none of the mRNA for these adhesion molecules were increased in the testis from Cadm1-deficient mice (data not shown). Furthermore, Mpzl2 mRNA showed no increase in the testis from Nectin-3-deficient mice, which also has impaired spermatogenesis. Taken together, these results suggest that the upregulation of Mpzl2 expression in Cadm1-deficient mouse testis is a specific phenomenon. The precise mechanisms underlying this upregulation are unclear. Although both of the genes for Mpzl2 and Cadm 1 are located on chromosome 9, their distance is as long as 
$2.5 \times 10^{6}$ nucleotides, their promoter regions are different, and their transcriptional control in the testis is largely unknown.

ISH demonstrated that the Mpzl2 mRNA is primarily expressed in the spermatocytes, and IHC further demonstrated that the Mpzl2 protein is localized in the leptotene/ zygotene through to early pachytene spermatocytes in both wild-type and Cadm-1-deficient mice. It should be noted that Cadm1-deficient mice have impaired spermatogenesis accompanied by prominent shedding of elongated spermatids into the lumen of seminiferous tubules, whereas the earlier spermatogenic cells up to early pachytene spermatocytes appeared intact. The presence of Mpzl2 in Cadm1positive earlier spermatogenic cells in contrast with the absence of Mpzl2 in Cadm1-positive elongated spermatids leads us to the hypothesis that Mpzl-2 and Cadm1 have functional redundancy in the seminiferous tubules. The deficiency of Cadm 1 may be compensated for by the increased amount of Mpzl2 in the earlier spermatogenic cells, whereas such compensation may not work in Mpzl2negative elongated spermatids, resulting in their detachment from Sertoli cells.

Elongated spermatids express, besides Cadm1, all of $\mathrm{N}$-cad, CAR, Jam-C, and Nectin-3. Among these cell adhesion molecules, Jam-C and Nectin-3, when deficient, cause the shedding of elongated spermatids as well as the malformation of the remaining elongated spermatids, similar to Cadm $1[6,8]$. Interestingly, Jam-C and Nectin-3, as well as Cadm1, have both homophilic and heterophilic binding activities, and interact not only with the same molecules but also with Jam-B, Nectin-2, and Pvr, respectively, that are expressed in Sertoli cells [27]. These adhesion molecules, that are expressed in elongated spermatids and indispensable for spermatogenesis, appear to be unable to compensate for the lack of the others. On the other hand, early spermatocytes have been known to express, besides Cadm1, no Jam-C or Nectin-3 but N-cad and CAR $[9,12]$. N-cad and CAR are also expressed in Sertoli cells and can be involved in the interaction between spermatogenic and Sertoli cells through homophilic binding. However, considering that N-cad [11] and CAR are unable to compensate for the lack of Cadm1, Jam-C or Nectin-3 in elongated spermatids, they are more likely responsible for the interaction between Sertoli cells. Since the present ISH results indicated that Mpzl2 is not expressed in Sertoli cells, the compensatory function of Mpzl2 on Cadm1 may be based on its heterophilic binding with Pvr, the known binding partner of Cadm1, or some other yet unidentified adhesion molecule present on Sertoli cells. So far, no molecule has been reported as the heterophilic binding partner of Mpzl2. Further studies are required to clarify this issue. On the other hand, the homophilic binding activity of Mpzl2, as well as that of Cadm1, JamC and Nectin-3, might be responsible for the interaction among spermatogenic cells for their synchronized development.

Spermatogenesis [19] is a process by which spermatogenic stem cells give rise to highly differentiated sperma- tozoa through the interaction of spermatogenic cells with somatic Sertoli cells. This process may require many cell adhesion molecules expressed on the surface of spermatogenic and Sertoli cells. The present study suggested that there is a complex functional redundancy among these adhesion molecules. In the case of the deficiency of one of these molecules, the presence or absence of compensation of the deficient molecule with another molecule may bring about a variety of phenotypes in seminiferous tubules. The double-knockout study targeting various combinations of these molecules may shed light on the biological significance of each molecule in spermatogenesis. To date only a few cell adhesion molecules have been proven to be essential for spermatogenesis. Although human male infertility is often idiopathic, some infertile patients may have defective spermatogenesis due to dysfunction of some of these cell adhesion molecules. We hope to identify such molecules in the future.

\section{Acknowledgments}

This work was supported by a Grant-in-Aid from the Ministry of Education, Science, and Culture of Japan, and by the Honjin Foundation to TW.

\section{References}

1. Bellvé, A. R., Cavicchia, J. C., Millette, C. F., O’Brien, D. A., Bhatnagar, Y. M. and Dym, M. (1997) Spermatogenic cells of the prepuberal mouse. Isolation and morphological characterization. J. Cell Biol. 74; 68-85.

2. Brümmendorf, T. and Rathjen, F. G. (1995) Cell adhesion molecules 1: immunoglobulin superfamily. Protein Profile 2; 963-1108.

3. Chatterjee, G., Carrithers, L. M. and Carrithers, M. D. (2008) Epithelial V-like antigen regulates permeability of the blood-CSF barrier. Biochem. Biophys. Res. Commun. 372; 412-417.

4. DeMonte, L., Porcellini, S., Tafi, E., Sheridan, J., Gordon, J., Depreter, M., Blair, N., Panigada, M., Sanvito, F., Merati, B., Albientz, A., Barthlott, T., Ozmen, L., Blackburn, C. C. and Guttinger, M. (2007) EVA regulates thymic stromal organisation and early thymocyte development. Biochem. Biophys. Res. Commun. 356; 334-340.

5. Fujita, E., Kouroku, Y., Ozeki, S., Tanabe, Y., Toyama, Y., Maekawa, M., Kojima, N., Senoo, H., Toshimori, K. and Momoi, T. (2006) Oligo-astheno-teratozoospermia in mice lacking RA175/TSLC1/SynCAM/IGSF4A, a cell adhesion molecule in the immunoglobulin superfamily. Mol. Cell. Biol. 26; 718-726.

6. Gliki, G., Ebnet, K., Aurrand-Lions, M., Imhof, B. A. and Adams, R. H. (2004) Spermatid differentiation requires the assembly of a cell polarity complex downstream of junctional adhesion molecule-C. Nature 431; 320-324.

7. Guttinger, M., Sutti, F., Panigada, M., Porcellini, S., Merati, B., Mariani, M., Teesalu, T., Consalez, G. G. and Grassi, F. (1998) Epithelial V-like antigen (EVA), a novel member of the immunoglobulin superfamily, expressed in embryonic epithelia with a potential role as homotypic adhesion molecule in thymus histogenesis. J. Cell Biol. 141; 1061-1071.

8. Inagaki, M., Irie, K., Ishizaki, H., Tanaka-Okamoto, M., Miyoshi, J. and Takai, Y. (2006) Role of cell adhesion molecule nectin-3 in spermatid development. Genes Cells 11; 1125-1132.

9. Johnson, K. J. and Boekelheide, K. (2002) Dynamic testicular 
adhesion junctions are immunologically unique. II. Localization of classic cadherins in rat testis. Biol. Reprod. 66; 992-1000.

10. Kuramochi, M., Fukuhara, H., Nobukuni, T., Kanbe, T., Maruyama, T., Ghosh, H. P., Pletcher, M., Isomura, M., Onizuka, M., Kitamura, T., Sekiya, T., Reeves, R. H. and Murakami, Y. (2001) TSLC1 is a tumor-suppressor gene in human non-smallcell lung cancer. Nat. Genet. 27; 427-430.

11. Kusumoto, K., Kikuchi, M., Fujiwara, K., Horiguchi, K., Kouki, T., Kawanishi, K. and Yashiro, T. (2010) Effect of E-cadherin expression on hormone production in rat anterior pituitary lactotrophs in vitro. Acta Histochem. Cytochem. 43; 83-88.

12. Mirza, M., Hreinsson, J., Strand, M. L., Hovatta, O., Söder, O., Philipson, L., Pettersson, R. F. and Sollerbrant, K. (2006) Coxsackievirus and adenovirus receptor (CAR) is expressed in male germ cells and forms a complex with the differentiation factor JAM-C in mouse testis. Exp. Cell Res. 312; 817-830.

13. O'Donnell, L., Meachem, S. J., Stanton, P. G. and McLachlan, R. I. (2006) Endocrine regulation of spermatogenesis. In "Knobil and Neill's Physiology of Reproduction, 3rd ed", ed. by J. D. Neill, Academic Press, New York, pp. 1017-1069.

14. Ozaki-Kuroda, K., Nakanishi, H., Ohta, H., Tanaka, H., Kurihara, H., Mueller, S., Irie, K., Ikeda, W., Sakai, T., Wimmer, E., Nishimune, Y. and Takai, Y. (2002) Nectin couples cell-cell adhesion and the actin scaffold at heterotypic testicular junctions. Curr. Biol. 12; 1145-1150.

15. Sakisaka, T. and Takai, Y. (2004) Biology and pathology of nectins and nectin-like molecules. Curr. Opin. Cell Biol. 16; 513521.

16. Salanova, M., Ricci, G., Boitani, C., Stefanini, M., De Grossi, S. and Palombi, F. (1998) Junctional contacts between Sertoli cells in normal and aspermatogenic rat seminiferous epithelium contain alpha6betal integrins, and their formation is controlled by follicle-stimulating hormone. Biol. Reprod. 58; 371-378.

17. Schmittgen, T. D. and Livak, K. J. (2008) Analyzing real-time PCR data by the comparative C(T) method. Nat. Protoc. $3 ; 1101-$ 1108 .

18. Shingai, T., Ikeda, W., Kakunaga, S., Morimoto, K., Takekuni, K., Itoh, S., Satoh, K., Takeuchi, M., Imai, T., Monden, M. and Takai, Y. (2003) Implications of nectin-like molecule-2/IGSF4/ RA175/SgIGSF/TSLC1/SynCAM1 in cell-cell adhesion and transmembrane protein localization in epithelial cells. J. Biol. Chem. 278; 35421-35427.

19. Song, N., Liu, J., An, S., Nishino, T., Hishikawa, Y. and Koji, T. (2011) Immunohistochemical analysis of histone H3 modifications in germ cells during mouse spermatogenesis. Acta Histochem. Cytochem. 44; 183-190.
20. Surace, E. I., Strickland, A., Hess, R. A., Gutmann, D. H. and Naughton, C. K. (2006) Tslcl (nectin-like molecule-2) is essential for spermatozoa motility and male fertility. J. Androl. 27; 816-825.

21. Van der Weyden, L., Arends, M. J., Chausiaux, O. E., Ellis, P. J., Lange, U. C., Surani, M. A., Affara, N., Murakami, Y., Adams, D. J. and Bradley, A. (2006) Loss of TSLC1 causes male infertility due to a defect at the spermatid stage of spermatogenesis. Mol. Cell. Biol. 26; 3595-3609.

22. Wakayama, T., Ohashi, K., Mizuno, K. and Iseki, S. (2001) Cloning and characterization of a novel mouse immunoglobulin superfamily gene expressed in early spermatogenic cells. Mol. Reprod. Dev. 60; 158-164.

23. Wakayama, T., Koami, H., Ariga, H., Kobayashi, D., Sai, Y., Tsuji, A., Yamamoto, M. and Iseki, S. (2003) Expression and functional characterization of the adhesion molecule spermatogenic immunoglobulin superfamily in the mouse testis. Biol. Reprod. 68; 1755-1763.

24. Wakayama, T., Koami, H., Yamamoto, M. and Iseki, S. (2004) Expression of the adhesion molecule spermatogenic immunoglobulin superfamily (SgIGSF). Acta Histochem. Cytochem. 37; 365-371.

25. Wakayama, T., Kato, Y., Usumi, R., Tsuji, A. and Iseki, S. (2006) A time and cost-saving method of producing rat polyclonal antibodies. Acta Histochem. Cytochem. 39; 79-87.

26. Wakayama, T., Sai, Y., Ito, A., Kato, Y., Kurobo, M., Murakami, Y., Nakashima, E., Tsuji, A., Kitamura, Y. and Iseki, S. (2007) Heterophilic binding of the adhesion molecules poliovirus receptor and immunoglobulin superfamily $4 \mathrm{~A}$ in the interaction between mouse spermatogenic and Sertoli cells. Biol. Reprod. 76; 1081-1090.

27. Wakayama, T. and Iseki, S. (2009) Role of the spermatogenicSertoli cell interaction through cell adhesion molecule-1 (CADM1) in spermatogenesis. Anat. Sci. Int. 84; 112-121.

28. Yamada, D., Yoshida, M., Williams, Y. N., Fukami, T., Kikuchi, S., Masuda, M., Maruyama, T., Ohta, T., Nakae, D., Maekawa, A., Kitamura, T. and Murakami, Y. (2006) Disruption of spermatogenic cell adhesion and male infertility in mice lacking TSLC1/IGSF4, an immunoglobulin superfamily cell adhesion molecule. Mol. Cell. Biol. 26; 3610-3624.

This is an open access article distributed under the Creative Commons Attribution License, which permits unrestricted use, distribution, and reproduction in tion License, which permits unrestricted use, distribution,
any medium, provided the original work is properly cited. 